\title{
Aerial Survey as a Tool to Estimate Abundance and Describe Distribution of a Carcharhinid Species, the Lemon Shark, Negaprion brevirostris
}

\author{
S. T. Kessel, ${ }^{1,2,3}$ S. H. Gruber, ${ }^{2}$ K. S. Gledhill, ${ }^{2}$ M. E. Bond, ${ }^{1,2}$ and R. G. Perkins ${ }^{1}$ \\ ${ }^{1}$ School of Earth and Ocean Sciences, Cardiff University, Cardiff CF10 3AT, UK \\ ${ }^{2}$ Bimini Biological Field Station, 15 Elizabeth Drive, South Bimini, Bahamas \\ ${ }^{3}$ University of Windsor, Great Lakes Institute for Environmental Research, 401 Sunset Avenue, \\ Windsor, ON, Canada N9B 3P4
}

Correspondence should be addressed to S. T. Kessel; skessel@uwindsor.ca

Received 23 April 2013; Revised 6 August 2013; Accepted 2 September 2013

Academic Editor: Susumu Ohtsuka

Copyright (c) 2013 S. T. Kessel et al. This is an open access article distributed under the Creative Commons Attribution License, which permits unrestricted use, distribution, and reproduction in any medium, provided the original work is properly cited.

\begin{abstract}
Aerial survey provides an important tool to assess the abundance of both terrestrial and marine vertebrates. To date, limited work has tested the effectiveness of this technique to estimate the abundance of smaller shark species. In Bimini, Bahamas, the lemon shark (Negaprion brevirostris) shows high site fidelity to a shallow sandy lagoon, providing an ideal test species to determine the effectiveness of localised aerial survey techniques for a Carcharhinid species in shallow subtropical waters. Between September 2007 and September 2008, visual surveys were conducted from light aircraft following defined transects ranging in length between 8.8 and $4.4 \mathrm{~km}$. Count results were corrected for "availability", "perception", and "survey intensity" to provide unbiased abundance estimates. The abundance of lemon sharks was greatest in the central area of the lagoon during high tide, with a change in abundance distribution to the east and western regions of the lagoon with low tide. Mean abundance of sharks was estimated at 49 ( \pm 8.6$)$ individuals, and monthly abundance was significantly positively correlated with mean water temperature. The successful implementation of the aerial survey technique highlighted the potential of further employment for shark abundance assessments in shallow coastal marine environments.
\end{abstract}

\section{Introduction}

Aerial survey has been used as a tool to assess species abundance for both terrestrial and marine vertebrates, often where the remoteness or vastness of the survey area and the potentially low abundance of the study species render other techniques uneconomical [1-6]. In the marine environment, aerial survey has typically focused on air breathing marine mammals and reptiles [2,7-13] because these taxa are regularly visible at the surface. Through aerial surveys, it has been possible to quantify the abundance of marine creatures in remote locations. A few examples of these are dense concentrations of narwhal (Monodon monoceros) in the offshore pack ice of Baffin Bay, West Greenland [14] and the seasonal distribution of crabeater seals (Lobodon carcinophagus) in the pack ice of Antarctica [15]. In addition, aerial surveys have revealed unique insights into marine creatures, for example, the specific birthing location of an endangered western North Atlantic right whale (Eubalaena glacialis) [16] and mass aggregations of whale sharks (Rhincodon typus), numbering up to 420 individuals, previously not witnessed [17].

For sharks, aerial survey has been largely limited to the large filter feeding species, whale [18-20] and basking sharks (Cetorhinus maximus) [21, 22], as both these species spend long periods of time feeding near the surface, and their large size make them highly visible. In contrast to the large filter feeding species, most coastal shark species spend relatively little time at the surface, instead remaining near the seabed [23] or undertaking variable vertical diving profiles $[24,25]$. These behaviours make coastal species generally unsuitable for aerial survey; hence, to date limited 
aerial survey of coastal sharks has been undertaken. Initially, incidental accounts of sharks observed during aerial surveys designed to survey turtles and marine mammals were published for seasonal occurrence of hammerheads (Sphyrna spp.) in Cape Canaveral, Florida [26], and the distribution of various shark species in the northeast United States [27]. For surveys intended to focus on coastal sharks, Gruber et al. [28] conducted experimental surveys of the Bimini lagoon lemon sharks (Negaprion brevirostris) from an ultralight aircraft; then Reyier et al. [29] opportunistically surveyed juvenile lemon sharks aggregating along the Cape Canaveral shoreline, Florida. Most recently aerial surveys were used to identify a possible inshore white shark (Carcharodon carcharias) nursery in Algoa Bay, South Africa [30].

The lemon shark (Negaprion brevirostris; Poey 1868) is classified as a large coastal shark species [31]. Lemon sharks are one of the larger Carcharhinid species, reaching a maximum length of $260 \mathrm{~cm}$ Pre-Caudal Length (PCL), with both females and males reaching sexual maturity at around 12 years of age and $\sim 166 \mathrm{~cm}$ PCL [32, 33]. Three distinct ontogenetic life stages are recognised for lemon sharks; nursery-bound juvenile ( $45-80 \mathrm{~cm}$ PCL), subadult $(\sim 81-165 \mathrm{~cm}$ PCL), and adult/mature $(\sim 166+\mathrm{cm}$ PCL) [23, $34,35]$. They most commonly inhabit shallow subtropical waters around coral reefs, mangroves, seagrass beds, enclosed bays, sounds and river mouths [35]. Their diet consists mainly of bony fish and crustaceans [36-41]. Lemon sharks are viviparous, with a fecundity of 4-17 individuals [42]. Females display a biennial breeding cycle [42] and a high level of philopatry [43]; therefore the environmental health and state of specific nursery sites are important for breeding ecology. Lemon sharks are commercially targeted [31, 44], and their conservation status is currently listed as "Near Threatened" by the International Union for Conservation of Nature (IUCN) Red List, largely due to habitat degradation of nursery areas [45].

With increasing concern over the global status of shark populations [46] coupled with the inherent difficulties of studying large mobile marine predators, new techniques, which provide reliable species abundance estimates, are required. Aerial survey of coastal shark species in shallow subtropical waters, where water clarity and visibility are generally high, may provide such a tool. Through the use of small, low flying aircraft and visual survey, the aims of the study were to (1) estimate subadult lemon shark abundance in Bimini lagoon, (2) delineate the spatial distribution of subadult lemon shark abundance in the lagoon and variation relative to tidal state, (3) determine seasonal variations in subadult lemon shark abundance relative to water temperature, and (4) assess the effectiveness of aerial surveys for providing coastal shark abundance estimates.

\section{Materials and Methods}

2.1. Study Site. The Bimini islands, Bahamas $\left(25^{\circ} 44^{\prime} \mathrm{N}\right.$, $\left.79^{\circ} 16^{\prime} \mathrm{W}\right)$, are located on the western edge of the Great Bahama Bank, adjacent to the deep waters of the Gulf Stream (Figure 1). The two main islands, North and South Bimini, lie on either side of a shallow sandy lagoon measuring approximately $25 \mathrm{~km}^{2}$ and $\sim 1 \mathrm{~m}$ average depth. Lemon sharks have known nursery habitat in the Bimini islands, with the home range of individuals increasing with increasing size of animal. For the first three years of life, juveniles inhabit specific near shore mangrove primary nurseries, increasing their home range exponentially with each year of growth [37, 38, 47, 48]. At around four years of age they expand their movements and use the central lagoon for the duration of their subadult life stage [23, 28, 49]. The Bimini lagoon is a shallow $(\sim 1 \mathrm{~m})$, clear water environment, with a mostly light coloured sandy bottom (Figure 1), providing an ideal aerial viewing situation for detecting the darker lemon sharks swimming near or resting on the bottom (see [18]). Preliminary aerial observations at Bimini demonstrated the feasibility of this technique to provide realistic estimates of lemon shark abundance if conducted in a systematic way [28]. Due to the light coloured substratum and known subadult lemon shark site fidelity, the central lagoon was selected as the study site to be covered by the aerial survey.

2.2. Aerial Survey. The aerial survey design adopted stratified block sampling protocol following standard procedures [1, $3,18,50,51]$. The study area was divided into blocks using ArcGIS 10 (Figure 2), by dividing the central lagoon into near equal-sized sections with marker buoys, and then the rest of the survey area was divided into similar-sized blocks using existing landmarks. During each aerial survey, defined as one sampling event, a total of 10 transects were flown providing two passes for each block, one pass on the western edge when travelling north and one pass on the eastern edge when travelling south (Figure 2). Due to transects being positioned on the survey block edges, some of the survey tracked the lagoon shoreline. This would have potentially positively influenced abundance estimates if the subadult lemon sharks displayed a level of shoreline attachment/site fidelity. However, extensive acoustic tracking studies revealed no such patterns in their distribution, showing wide lemon shark distribution across the entire lagoon area [23, 52]. Therefore, no such positive influence was expected, and it was concluded that survey block edge transects would provide an unbiased sample of the survey region. The survey area covered during every sampling event, within each defined block, was then calculated from each strip transect (see below). Total survey time for each sampling event ranged from 27 to 32 minutes (mean $\pm \mathrm{SE}$ ) $30.62 \pm 0.5$. Aerial surveys were only conducted in wind conditions below Beaufort scale $3\left(12-19 \mathrm{kmh}^{-1}\right)$ : when cloud cover was $<30 \%$ and between $10: 00$ and $14: 00$, as close to $12: 00$ as possible and when the sun is at its highest point to minimise bias associated with these environmental conditions [3, 9, 18, 50, 53].

The aerial survey team consisted of four members: a pilot, two observers, and a survey monitor. Both observers were located on the starboard side of the aircraft adopting the dual observer technique [3]. The first observer was located in the front right seat facing right and forward ahead of the wing and the second observer in the rear of the aircraft facing right and backward behind the wing, eliminating the potential of 


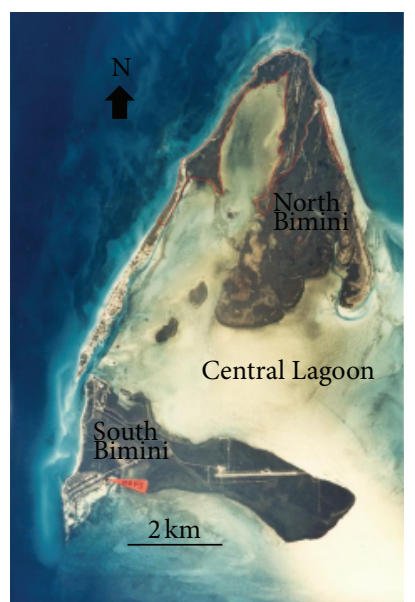

Figure 1: Aerial Photograph of the Bimini Islands with North Bimini above and South Bimini below encasing the study site, the shallow, sandy central lagoon.

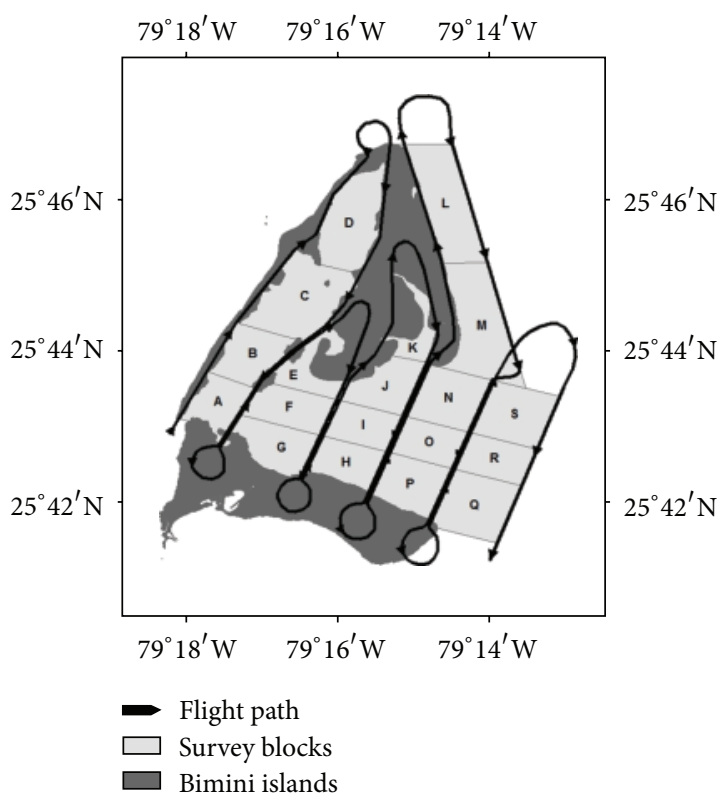

Figure 2: Aerial survey transect flight path depicted by the line. Arrows indicate the direction of the flight path. A-S represent stratified block sampling blocks.

visual obstruction in low winged aircraft. The two observers identified shark species, undertook counts for each block and recorded data on predefined survey sheets independently with no in-flight communication. The same two observers were used for all surveys to standardise potential observer bias. Both observers were trained and experienced in shark identification. Following the completion of a sampling event, observer survey data were examined, and the maximum count of sharks for each survey block, that is, the largest number of sharks observed by both or either of observers per block, was recorded. The survey monitor, located behind the pilot, recorded the GPS tracks of each transect to ensure accurate repeatability. Additionally, time of takeoff and landing, start and end time of each transect, altitude, cloud cover, wind speed, and wind direction were recorded.

Throughout the study period, four different aircrafts were used to undertake aerial surveys (Cessna 172, a Beechcraft 35 Bonanza, a Piper Pa-28 Archer, and a Piper PA-31-350 Navajo Chieftain). Each aircraft was similar in design, and therefore all surveys were conducted with team members located in the same positions and under the same flight conditions. For all sampling events $(n=8)$, aircrafts were flown at an altitude of $100 \mathrm{~m}$ and a groundspeed of $185 \mathrm{kmh}^{-1}$. We assumed that there was no movement of individual sharks between blocks during the duration of each aerial survey. This was based on the published average lemon shark swimming speed of $0.57 \mathrm{~ms}^{-1}$ [54]. The abundance estimate $(N)$ was calculated for each block using Rowat et al. [18] equation as follows

$$
N=\frac{(C \times \mathrm{ACF} \times \mathrm{PCF})}{\mathrm{SI}},
$$

where $C$ is the lemon shark count, ACF is the availability correction factor, PCF is the perception correction factor, and SI is the survey intensity (see definitions below). Finally, the sum of all block abundance estimates provided an abundance estimate for the total survey area.

2.3. Availability Correction Factor (ACF). The availability correction factor (ACF), also known as availability bias, accounts for potential sharks that were within a survey block but were not visible and therefore not counted. For animals in the marine environment, visual counts of individuals are normally restricted by water turbidity, water/animal depth, and diving behaviour $[1-3,18,19]$. In Bimini, the maximum water depth within the survey area was $<4 \mathrm{~m}$; thus water depth and diving behaviour were not considered to be variables affecting lemon shark availability for visual detection. Surveys were also restricted to calm conditions (wind $<12-19 \mathrm{kmh}^{-1}$ ) with little to no turbidity; therefore turbidity effects could be discounted. Thus, in this study, all sharks residing within the surveyed area during all surveys would be available to be counted.

2.4. Perception Correction Factor (PCF). The perception correction factor (PCF), also known as perception bias, accounts for the number of individual sharks not counted by the observers due to factors such as glare, fatigue, or inattention $[2,3]$. For aerial survey, the two greatest potential sources for perception error are aircraft altitude and observer error. For a given aircraft altitude, it may not be possible to see an individual of a given size, with increasing altitude decreasing the ability of observers to count small individuals. Marsh and Sinclair [3] reported that a ratio of "altitude: minimum animal size" of 274:1 enabled reliable detections. In the present study an aircraft altitude of $100 \mathrm{~m}$ was maintained, and the minimum animal target size was $\sim 1 \mathrm{~m}$ total length, providing a ratio of $100: 1$, well within the limits of reliable detection. Smaller juvenile lemon sharks, $<1 \mathrm{~m}$ total length, would have been difficult to distinguish and tend to avoid the exposed lagoon areas, segregating due to predation threat from larger conspecifics [52]. Therefore, identified individuals in the 
survey area were assumed to be subadults. PCF correction for altitude was therefore not required. Observers may simply miss or fail to identify individual animals within a survey area for a number of reasons that can vary between observers [3]. For this reason, two independent observers were used for each survey, and we adopted Marsh and Sinclair's [3] dual observer bias equation to correct for perception bias

$$
\mathrm{PCF}=\frac{\left(S_{m}+b\right)\left(S_{r}+b\right)}{b\left(S_{m}+S_{r}+b\right)},
$$

where " $S_{m}$ " is the number of sharks seen by observer 1 only, " $S_{r}$ " is the number of sharks seen by observer 2 only, and " $b$ " is the number of sharks seen by both observers.

2.5. Survey Intensity (SI). Survey intensity (SI) is the proportion of the total survey area sampled by the aerial survey and was calculated as follows [18]

$$
\mathrm{SI}=\frac{\text { area of coverage }}{\text { area of block }} \text {. }
$$

The SI value accounts for sharks that are potentially present in the area of the block not covered by the visual swath of the flight path. SI values were calculated for each block using ArcGIS 10. First, individual polygons were created for each of the aerial survey blocks to calculate the total area of each block. The effective visual transect width for each block during an aerial survey was established for the standard survey altitude and speed $\left(100 \mathrm{~m}\right.$ and $185 \mathrm{kmh}^{-1}$, resp.) using submerged markers $(100 \times 40 \mathrm{~cm})$. The submerged markers were made from plywood and positioned in the lagoon at $25 \mathrm{~m}$ distance intervals from a known location on the flight path. The number of markers visible was counted on a presurvey test flight to verify the visual transect width. As the test flight and all subsequent survey flights were conducted within the predefined survey conditions and due to the uniform characteristics of the survey area, it was assumed that visual transect width would remain relatively constant between surveys. ArcGIS 10 was used to calculate the survey area, visually covered, by "buffering" (ArcGIS tool) the flight path with the calculated visual transect width. Area of coverage was then obtained by the "union" (ArcGIS tool) of the block polygons, with the visual transect width buffer. By this union process, each block polygon was divided into three subsequent polygons; two of which represented the visual area of coverage for the north and south line transects. The combined areas of the two isolated visual coverage polygons provided the area of coverage.

2.6. Lemon Shark Abundance. For each survey, lemon shark abundance for each block was calculated and then summed to give a total abundance estimate for the entire survey area. The calculated abundance for each block was then divided by the area of that block to give an abundance value expressed as $\mathrm{NB} / \mathrm{km}^{2}$. Calculated $\mathrm{NB} / \mathrm{km}^{2}$ values for all survey events were combined for each block and then divided by the number of surveys conducted to give mean unit effort (UE) for lemon shark abundance per block. This was then mapped in ArcGIS
10 to provide a spatial depiction of the results. Aerial survey events were then divided into low- and high-tide counts, and the above calculations were repeated. Percent change of the raw count data from high to low tide was calculated for each survey block and mapped in ArcGIS 10. The Chi-squared $\left(\chi^{2}\right)$ analysis was conducted on the raw count data to test if there was significant variation $(P<0.05)$ for survey blocks between tidal states, with the null hypothesis that block abundance would be equal.

2.7. Water Temperature Monitoring. Mean monthly water temperatures $\left({ }^{\circ} \mathrm{C}\right)$ were obtained from 15 thermochron (iButton) temperature loggers deployed across study area. Spearman's rank correlation was used to test for a significant relationship $(P<0.05)$ between total monthly abundance estimates and mean monthly water temperatures, for all surveys, and then repeated for low tide surveys only to eliminate any potential influence of tidal state over lemon shark abundance.

\section{Results}

3.1. Survey Summary. A total of eight aerial surveys were conducted between September 2007 and September 2008, two at high tide and six at low tide. In all surveys, a total of 212 sharks of three species, lemon (145), nurse (Ginglymostoma cirratum; 42), and blacktip (Carcharhinus limbatus; 25) sharks, were recorded in the study area. Two additional species, tiger (Galeocerdo cuvier) and bull (Carcharhinus leucas) sharks, were identified from the air, but they were only present outside of the survey area and therefore not counted.

3.2. Correction Factors and Survey Intensity. For the availability correction factor (ACF), no factors were limiting the availability of sharks present in the surveyed area; therefore an ACF of 1 was applied. Perception correction factor (PCF) values ranged between surveys from 1.13 to 1.4 (mean = $1.28 \pm 0.03$; Table 1). The visual transect width, calculated from the submerged markers, was found to be $350 \mathrm{~m}$ for both observers. This distance may appear to be large for an observational altitude of $100 \mathrm{~m}$, but it was facilitated by the shallow waters, uniform light sandy substrate, and relative high contrast of the target species. Block survey intensity (SI) ranged from 0.332 to 0.885 (mean $=0.521 \pm 0.029$; Table 2$)$.

3.3. Lemon Shark Abundance Estimates. Mean lemon shark abundance for the entire survey period was 49 ( \pm 8.6$)$ individuals, ranging from a minimum 16 sharks in March 2008 to a maximum of 80 sharks in September 2008. Lemon shark abundance was generally higher in the summer months relative to the winter, a trend present when considering all surveys, high and low tide, and low tide surveys only (Figure 3). Mean monthly lemon shark abundance estimates were significantly correlated with mean monthly water temperature both for all surveys $(r=0.78, n=8, P<0.05)$ and surveys conducted only at low tide $(r=0.88, n=6, P<0.05)$. For all eight aerial survey events, the highest abundance of lemon sharks was recorded in the most central blocks E-J 
TABLE 1: Perception correction factor (PCF) values for each aerial survey, where " $S_{m}$ " is the number of sharks seen by observer 1 only, " $S_{r}$ " is the number of sharks seen by observer 2 only, and " $b$ " is the number of sharks seen by both observers.

\begin{tabular}{|c|c|c|c|c|c|}
\hline Survey date & Total lemon sharks observed & $b$ & $S_{m}$ & $S_{r}$ & $\mathrm{PCF}$ \\
\hline Sep-07 & 24 & 9 & 7 & 8 & 1.26 \\
\hline Nov-07 & 18 & 6 & 4 & 8 & 1.30 \\
\hline Dec-07 & 10 & 3 & 4 & 3 & 1.40 \\
\hline Jan-08 & 16 & 6 & 5 & 5 & 1.26 \\
\hline Mar-08 & 6 & 2 & 2 & 2 & 1.33 \\
\hline May-08 & 12 & 6 & 3 & 3 & 1.13 \\
\hline Jul-08 & 26 & 9 & 8 & 9 & 1.31 \\
\hline Sep-08 & 33 & 13 & 10 & 10 & 1.23 \\
\hline
\end{tabular}

TABLE 2: Area of block $\left(\mathrm{m}^{2}\right)$, area of coverage $\left(\mathrm{m}^{2}\right)$ based on $350 \mathrm{~m}$ visual swath width, and survey intensity (SI) of each survey block A-S.

\begin{tabular}{lccc}
\hline Survey block & Area of block $\left(\mathrm{m}^{2}\right)$ & Area of coverage $\left(\mathrm{m}^{2}\right)$ & SI \\
\hline A & $1,372,459$ & 883,975 & 0.644 \\
B & $1,629,582$ & 803,130 & 0.493 \\
C & $3,034,218$ & $1,259,041$ & 0.415 \\
D & $2,550,267$ & $1,385,899$ & 0.543 \\
E & $1,253,667$ & 842,485 & 0.672 \\
F & $1,626,326$ & 674,328 & 0.415 \\
G & $1,720,557$ & 571,343 & 0.332 \\
H & $1,471,679$ & 681,739 & 0.463 \\
I & $1,427,818$ & 658,329 & 0.461 \\
J & $1,657,296$ & 897,071 & 0.541 \\
K & 745,701 & 660,251 & 0.885 \\
L & $2,864,207$ & $1,910,109$ & 0.667 \\
M & $3,225,809$ & $1,871,598$ & 0.580 \\
N & $2,019,770$ & 955,687 & 0.473 \\
O & $1,407,947$ & 667,035 & 0.474 \\
P & $1,811,735$ & 850,333 & 0.469 \\
Q & $2,253,654$ & $1,009,107$ & 0.448 \\
R & $1,450,254$ & 663,801 & 0.458 \\
S & $2,038,271$ & 942,918 & 0.463 \\
\hline
\end{tabular}

and N-P (Figure 4(a)). The overall highest abundance was recorded in block $\mathrm{F}\left(6.17 \mathrm{NB} / \mathrm{km}^{2}\right)$ and the lowest in block $\mathrm{Q}\left(0.16 \mathrm{NB} / \mathrm{km}^{2}\right)$. The mean lemon shark abundance of all blocks was $1.15 \pm 0.33 \mathrm{NB} / \mathrm{km}^{2}$.

The abundance distribution of lemon sharks varied between high and low tides, although a disproportionate number of low tide surveys relative to high-tide surveys were flown. From high to low tide, there was a change in abundance distribution from the centre of the lagoon with blocks A-B and $\mathrm{G}-\mathrm{K}$ showing a decrease in abundance, while all other blocks showed an increase in abundance (Figures 4(b) and 5). From high to low tide surveys, mean lemon shark abundance $\left(\mathrm{NB} / \mathrm{km}^{2}\right)$ in block $\mathrm{G}$ and block I showed a highly significant decrease $\left(\chi^{2}=30.1\right.$, d.f. $\left.=1, P<0.001\right)$, and block I showed a significant decrease $\left(\chi^{2}=5.0\right.$, d.f. $\left.=1, P<0.05\right)$. Block $\mathrm{F}$ showed a highly significant increase $\left(\chi^{2}=26.9\right.$, d.f. $=$ $1, P<0.001)$, and block $\mathrm{O}$ showed a significant increase $\left(\chi^{2}=6.7\right.$, d.f. $\left.=1, P<0.01\right)$. Overall, two surveys were conducted on neap tide, five on half tides, and one on a spring tide. Mean tidal variation for all surveys was $0.63 \mathrm{~m}$ (range $=0.04-0.3 \mathrm{~m})$. For surveys conducted at high tide, one was conducted on a neap tide and one on a half tide (mean variation $=0.54 \pm \mathrm{SE} 0.04$ ). For surveys conducted at low tide, one was conducted on neap tide, four on half tide, and one on spring tide (mean variation $=0.65 \pm$ SE 0.04). Given the low tidal variability between surveys, we assume that tidal type did not have a strong influence over abundance distribution.

\section{Discussion}

This study represents the first successful focused employment of the aerial survey technique on a Carcharhinid species. This is useful not only for providing abundance estimates in a much shorter temporal scale than other methods, such as tag recapture estimates, but also for defining distribution without the potential biases. Sample biases can result from the use of longlines, where sharks can be attracted to the given areas by the bait [55], or active tracking, where the behaviour of the sharks can be altered by the presence of the boat [56]. In Bimini, aerial survey has shown the mean abundance of subadult lemons sharks to be 49 individuals, with the highest distribution of abundance in the centre of the lagoon and significantly influenced by tidal state. Observed abundance was also significantly positively correlated with water temperature, resulting in abundance variation across the course of the study. The aerial survey technique allowed for comprehensive abundance estimates, with equal sampling effort over a large area of secondary nursery, including otherwise hard to access areas due to very shallow water depths.

The block abundance of lemon sharks is highest in the central region of the lagoon (Figure 4(a)), which is the shallowest section of the lagoon and can even be exposed at spring low tide (personal observations 2002-2009; [28]). This is consistent with past life history data describing an ontogenetic shift from the near-shore mangrove fringed nurseries to the more open but shallow central lagoon area at the subadult life stage $[23,34,48]$. Despite disproportion in the surveying of the two tidal states (high $n=2$ and low $n=6$ ) the change in abundance distribution between tidal states is consistent with results of several acoustic tracking studies 


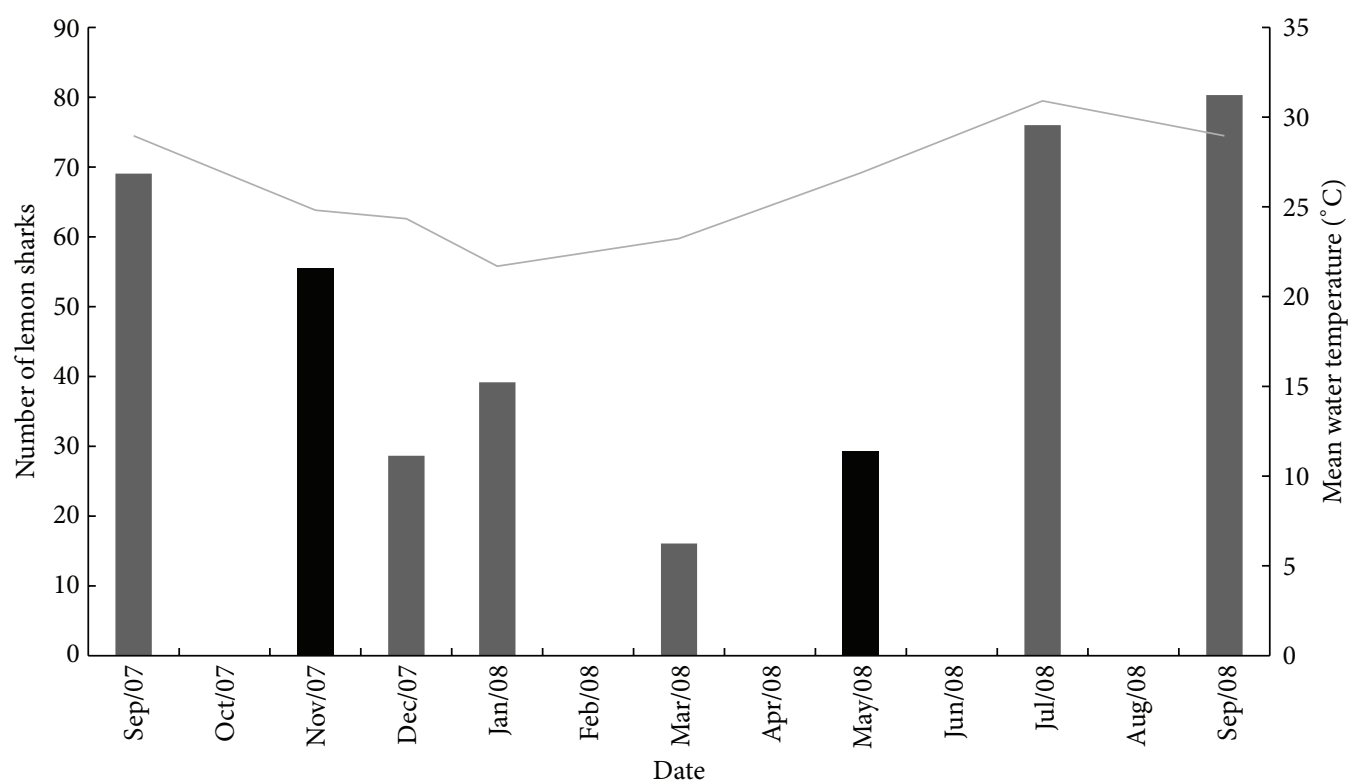

FIGURE 3: Lemon shark total abundance (number of lemon sharks) estimates by date, derived from aerial survey counts. Line graph represents mean monthly water temperature $\left({ }^{\circ} \mathrm{C}\right)$; grey bars represent surveys conducted at low tide, and black bars represent surveys conducted at high tide.

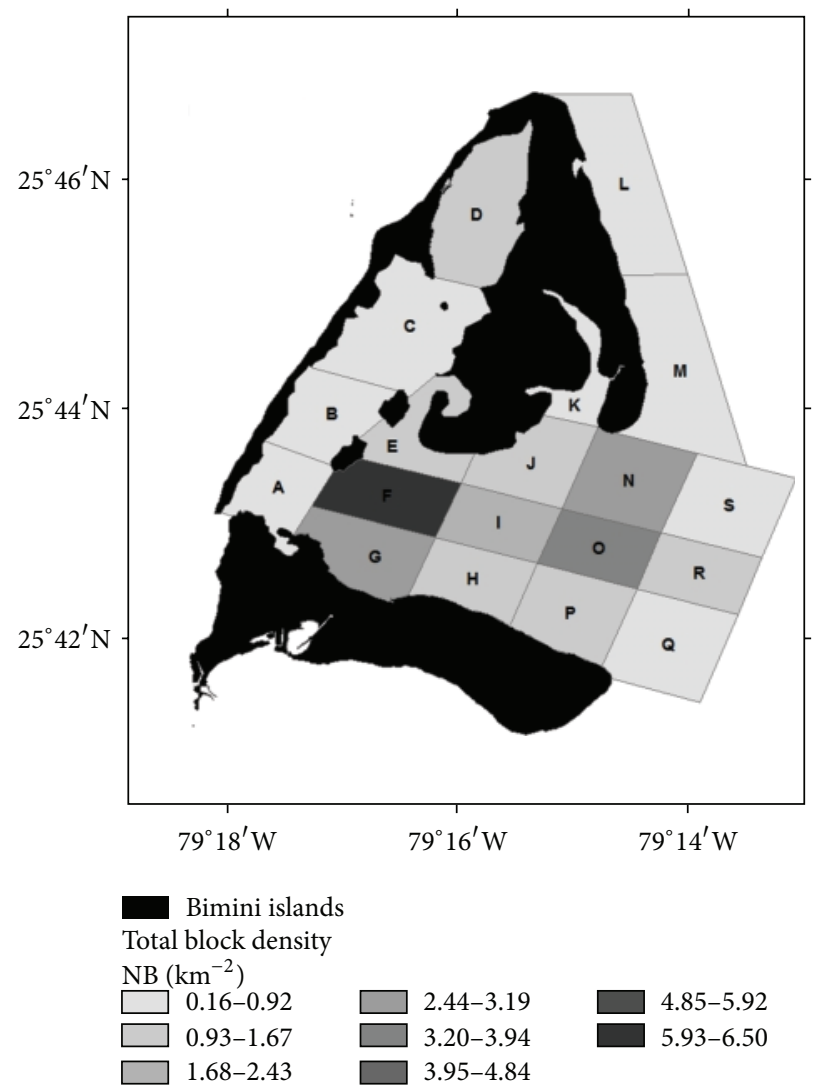

(a)

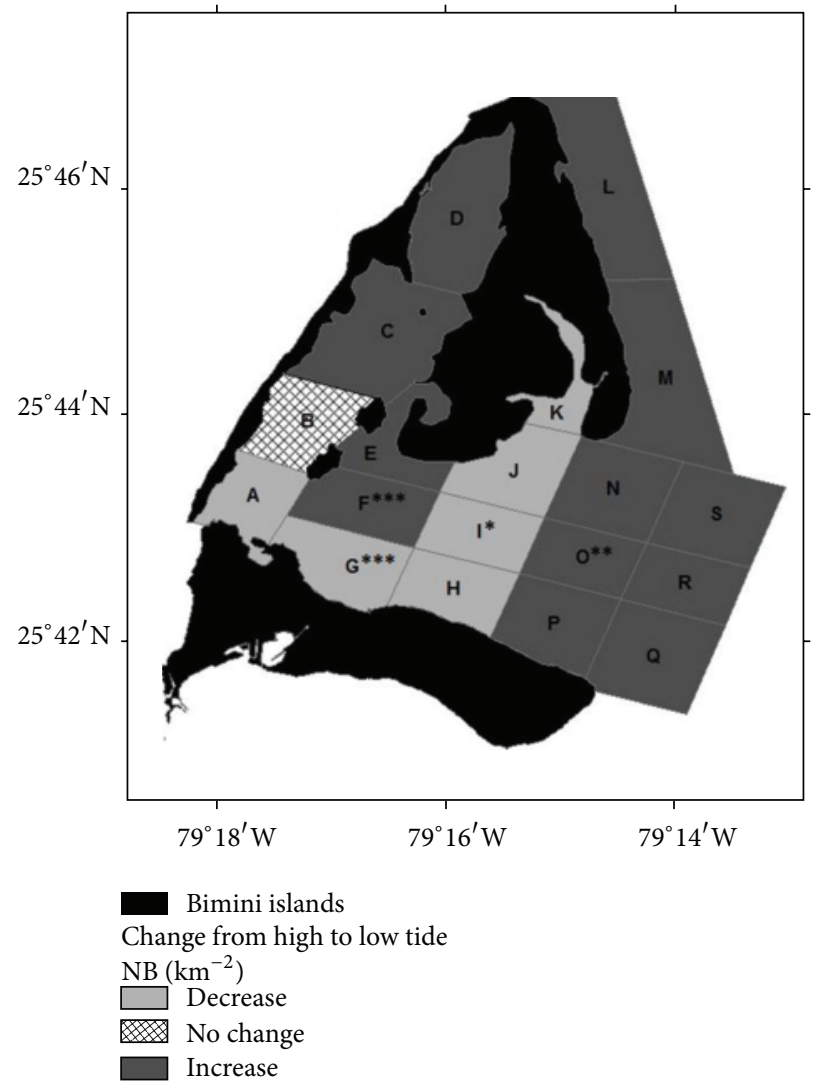

(b)

FIGURE 4: (a) Mean lemon shark block abundance for all surveys conducted; (b) change in block lemon shark count per unit effort (UE) from high-tide to low-tide surveys. Dark grey blocks represent an increase in count per UE; light grey block represents a decrease in count per UE; patterned block represents no change in count per UE, $\chi^{2}$ significant ${ }^{*} P<0.05,{ }^{* *} P<0.01,{ }^{* * *} P<0.001$. 


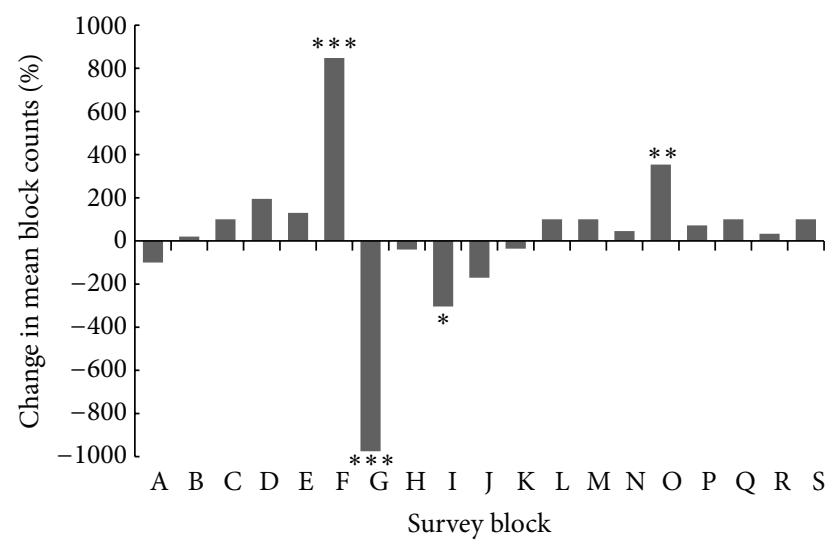

Figure 5: Percent change in mean lemon shark block counts (unit effort; UE) from high tide to low (positive) and low to high (negative) tide surveys; $\chi^{2}$ significant $P$ values denoted by ${ }^{*} P<$ $0.05,{ }^{* *} P<0.01,{ }^{* * *} P<0.001$.

$[23,28,52,55]$. The spatial change in abundance distribution, with the central areas of the lagoon showing high abundance at high tide and low abundance at low tide (Figures 4(b) and 5), was probably the result of decreased water depth making the central area physically uninhabitable at the low tidal state. The significant tidal changes in abundance for block I and block $\mathrm{O}$ and highly significant changes for block $\mathrm{F}$ and block $\mathrm{G}$ are consistent with areas of the lagoon where habitability is greatly affected by tidal change. Block $G$ and block I are particularly shallow areas that become almost dry during extreme low tides. Thus, sharks would not have been able to physically inhabit these areas at low tide. Block $\mathrm{O}$ is adjacent to block I, but it still retains a sufficient water depth at low tide to accommodate lemon sharks, with water depth progressively increasing to the east. Block F contains a large deep section $(\sim 1.5 \mathrm{~m})$ that at low tide is cut off from large predator risk by surrounding shallow water, but it remains deep enough for lemon sharks to inhabit. This potential lowtide refuge function, plus its adjacency to block $G$ showing high abundance at high tide, is a probable driver for the highly significant increase in abundance between high and low tide.

Water depth appears to be defining the lemon shark's distribution, with the shallowest inhabitable areas being favoured. The Bimini lagoon area has been previously described as a secondary nursery for lemon sharks, indicating that it offers the inhabiting individuals some form of protection from potential predators $[23,28]$. As the Bimini lagoon is generally homogenous with little structure present to offer physical protection, the shallow nature of the lagoon may offer protection through limited water depth. The central area is generally the shallowest; therefore, it is generally inaccessible to larger sharks that might pose a predation risk to smaller lemon sharks. As the tide falls, the central area becomes uninhabitable, forcing the lemon sharks into other areas that retain sufficient water depth. These other areas, towards the edges of the lagoon, then offer a shallow refuge as they have reduced in water depth with the falling tide. With a distribution influenced by predation risk, tidal driven abundance distribution changes are expected, and they have been commonly documented in other primary and secondary nurseries for several shark species [49, 52, 57-61]. The results of this study support the description of the central lagoon as a secondary nursery for lemon sharks.

Monthly variations in abundance, independent of tidal variations, were recorded and would be logical for a life stage or species that is known to display large scale seasonal movements [18]. Chapman et al. [49] found that $51.3 \%$ of subadult lemon sharks genetically sampled in the Bimini lagoon were born into Bimini nurseries. Thus, $48.7 \%$ were born elsewhere, and due to the relative isolation of the Bimini islands from any other suitable lemon shark nursery sites $(\sim 115 \mathrm{~km}$ to the nearest mangrove fringed island), the subadult lemon sharks are able to undertake large movements at this life stage. The significant relationship found between abundance and mean monthly water temperature indicates that, as documented for other Carcharhinid species [62], water temperature could have been driving seasonal abundance variation in the Bimini lagoon. Lemon shark temperature preferences may have resulted in seasonal latitudinal migrations. It is possible that individuals could travel to the more southern Bahamian islands on the great Bahama Bank, such as Andros, where the water temperatures may be more favourable in the winter months. Around the Bimini islands themselves, the lemon sharks may have moved to the deeper and warmer waters on the edge of the adjacent Gulf Stream, a behaviour exhibited by other ectothermic shark species in response to temperature change $[60,63]$; however this may result in a considerable increase in predation risk.

It is possible that decreased lemon shark metabolism in response to decreased water temperatures resulted in decreased activity [64-70]. Lemon sharks were more visible when in motion relative to the surrounding habitat (personal observation, 2007-2008); therefore, active individuals may have been more likely to be recorded than resting individuals. Thus, the recorded reduction in abundance correlated to water temperature reduction may have been partly exaggerated to due to the increased perception error in the winter months.

The aerial survey technique proved effective for establishing lemon shark abundance estimates for the Bimini lagoon. Sharks were easily visible from the aircraft, and the lemon shark was easily distinguished from the other species present, due to their signature fin assemblage, colour, and swimming motion. Perception correction factor (PCF) values were reasonable relative to past studies focused on other marine vertebrates [71]. Abundance distribution was easily established, and it was consistent with past telemetry studies both in general distribution and tidal driven distribution variation $[23,28,37,52]$. The consistency of distribution results, coupled with the results of the extensive number of lemon shark acoustic telemetry studies conducted in the survey area, indicates that the stratified block sampling design provided a representative subsample of the total lemon shark abundance. Subadult lemon sharks have been shown to use the full extent of the survey area, with no strong site fidelity to areas within the survey blocks not covered by the survey transects $[23,52]$. Thus, the application of 
the appropriate correction factors presented in this study would have been successful in extrapolating representative abundance estimates across the entire survey area.

This represented the first employment of the aerial survey technique for the abundance assessment of a Carcharhinid species. With global concern over declines in shark abundance resulting from target fisheries and bycatch [46, 72-74], it is imperative that new methods for assessing regional shark abundance have to be identified. The success of the aerial survey approach in Bimini highlighted the potential for further employment of this research technique for shark population assessments in similar habitats. It should be noted, however, that the survey design employed in this study was relatively basic as it was facilitated by the highly favourable conditions of this study site. For more challenging environments, a more complex survey design may be required to achieve reliable and representative abundance estimates (see Buckland [75]). The aerial survey technique would be proved effective for any area where sharks have a high level of site fidelity to clear shallow waters. For example, this technique would be particularly useful for shallow coastal beach areas that are commonly the boundary of human and shark interactions that result in both social and conservation issues.

\section{Acknowledgments}

First and foremost, the authors would like to acknowledge all the volunteer pilots that provided their time and aircraft for this study, namely, Bill Signs, Steve Gallagher, Joe Clawges, Brad and Juliet Michael, Kevin Lorio, and Joey Farrell. The authors thank Nigel Hussey, Gordon Paterson, Joseph DiBattista, David Jennings, and Abby Nease for providing help and advice in the preparation process and Douglas Norris for logistical support. The authors would also like to thank the three anonymous reviewers for their comments on the earlier draft of this paper, which greatly improved the current version.

\section{References}

[1] H. Marsh and W. K. Saalfeld, "Aerial surveys of sea turtles in the northern Great Barrier Reef Marine Park," Australian Wildlife Research, vol. 16, no. 3, pp. 239-249, 1989.

[2] E. Slooten, S. M. Dawson, and W. J. Rayment, "Aerial surveys for coastal dolphins: abundance of Hector's dolphins off the South Island west coast, New Zealand," Marine Mammal Science, vol. 20, no. 3, pp. 477-490, 2004.

[3] H. Marsh and D. F. Sinclair, "Correcting for visibility bias in strip transect aerial surveys of aquatic fauna," Journal of Wildlife Management, vol. 53, no. 4, pp. 1017-1024, 1989.

[4] G. P. Edwards, K. Saalfeld, and B. Clifford, "Population trend of feral camels in the Northern Territory, Australia," Wildlife Research, vol. 31, no. 5, pp. 509-517, 2004.

[5] S. D. Miller, R. P. Reading, B. Haskins, and D. Stern, "Overestimation bias in estimate of black-tailed prairie dog abundance in Colorado," Wildlife Society Bulletin, vol. 33, no. 4, pp. 1444-1451, 2005.

[6] R. M. Fewster and A. R. Pople, "A comparison of markrecapture distance-sampling methods applied to aerial surveys of eastern grey kangaroos," Wildlife Research, vol. 35, no. 4, pp. 320-330, 2008.

[7] L. Cardona, M. Revelles, C. Carreras, M. San Félix, M. Gazo, and A. Aguilar, "Western Mediterranean immature loggerhead turtles: habitat use in spring and summer assessed through satellite tracking and aerial surveys," Marine Biology, vol. 147, no. 3, pp. 583-591, 2005.

[8] B. A. Craig and J. E. Reynolds III, "Determination of manatee population trends along the Atlantic coast of Florida using a Bayesian approach: with temperature-adjusted aerial survey data," Marine Mammal Science, vol. 20, no. 3, pp. 386-400, 2004.

[9] H. H. Edwards, K. H. Pollock, B. B. Ackerman, J. E. Reynolds III, and J. A. Powell, "Estimation of detection probability in manatee aerial surveys at a winter aggregation site," Journal of Wildlife Management, vol. 71, no. 6, pp. 2052-2060, 2007.

[10] K. H. Pollock, H. D. Marsh, I. R. Lawler, and M. W. Alldredge, "Estimating animal abundance in heterogeneous environments: an application to aerial surveys for dugongs," Journal of Wildlife Management, vol. 70, no. 1, pp. 255-262, 2006.

[11] D. Roos, D. Pelletier, S. Ciccione, M. Taquet, and G. Hughes, "Aerial and snorkelling census techniques for estimating green turtle abundance on foraging areas: a pilot study in Mayotte Island (Indian Ocean)," Aquatic Living Resources, vol. 18, no. 2, pp. 193-198, 2005.

[12] A.-B. Salberg, T. A. Oøigård, G. B. Stenson, T. Haug, and K. T. Nilssen, "Estimation of seal pup production from aerial surveys using generalized additive models," Canadian Journal of Fisheries and Aquatic Sciences, vol. 66, no. 5, pp. 847-858, 2009.

[13] M. J. Witt, B. Baert, A. C. Broderick et al., "Aerial surveying of the world's largest leatherback turtle rookery: a more effective methodology for large-scale monitoring," Biological Conservation, vol. 142, no. 8, pp. 1719-1727, 2009.

[14] K. L. Laidre and M. P. Heide-Jørgensen, "Life in the lead: extreme densities of narwhals Monodon monoceros in the offshore pack ice," Marine Ecology Progress Series, vol. 423, pp. 269-278, 2011.

[15] M. N. Bester, A. W. Erickson, and J. W. Ferguson, "Seasonal change in the distribution and density of seals in the pack ice off Princess Martha Coast, Antarctica," Antarctic Science, vol. 7, no. 4, pp. 357-364, 1995.

[16] H. J. Foley, R. C. Holt, R. E. Hardee et al., "Observations of a western North Atlantic right whale (Eubalaena glacialis) birth offshore of the protected southeast U.S. critical habitat," Marine Mammal Science, vol. 27, no. 3, pp. E234-E240, 2011.

[17] R. de la Parra Venegas, R. Hueter, J. G. Cano et al., "An unprecedented aggregation of whale sharks, Rhincodon typus, in Mexican coastal waters of the Caribbean sea," PLoS ONE, vol. 6, no. 4, Article ID e18994, 2011.

[18] D. Rowat, M. Gore, M. G. Meekan, I. R. Lawler, and C. J. A. Bradshaw, "Aerial survey as a tool to estimate whale shark abundance trends," Journal of Experimental Marine Biology and Ecology, vol. 368, no. 1, pp. 1-8, 2009.

[19] G. Cliff, M. D. Anderson-Reade, A. P. Aitken, G. E. Charter, and V. M. Peddemors, "Aerial census of whale sharks (Rhincodon typus) on the northern KwaZulu-Natal coast, South Africa," Fisheries Research, vol. 84, no. 1, pp. 41-46, 2007.

[20] J. C. Sleeman, M. G. Meekan, S. G. Wilson et al., "Biophysical correlates of relative abundances of marine megafauna at Ningaloo Reef, Western Australia," Marine and Freshwater Research, vol. 58, no. 7, pp. 608-623, 2007.

[21] D. W. Sims, E. J. Southall, G. A. Tarling, and J. D. Metcalfe, "Habitat-specific normal and reverse diel vertical migration in 
the plankton-feeding basking shark," Journal of Animal Ecology, vol. 74, no. 4, pp. 755-761, 2005.

[22] S. G. Wilson, "Basking sharks (Cetorhinus maximus) schooling in the southern Gulf of Maine," Fisheries Oceanography, vol. 13, no. 4, pp. 283-286, 2004.

[23] L. F. Sundström, S. H. Gruber, S. M. Clermont et al., "Review of elasmobranch behavioral studies using ultrasonic telemetry with special reference to the lemon shark, Negaprion brevirostris, around Bimini Islands, Bahamas," Environmental Biology of Fishes, vol. 60, no. 1-3, pp. 225-250, 2001.

[24] K. N. Holland, B. M. Wetherbee, C. G. Lowe, and C. G. Meyer, "Movements of tiger sharks (Galeocerdo cuvier) in coastal Hawaiian waters," Marine Biology, vol. 134, no. 4, pp. 665-673, 1999.

[25] D. D. Chapman, E. K. Pikitch, E. A. Babcock, and M. S. Shivji, "Deep-diving and diel changes in vertical habitat use by Caribbean reef sharks Carcharhinus perezi," Marine Ecology Progress Series, vol. 344, pp. 271-275, 2007.

[26] R. D. Jennings, "Seasonal Abundance of Hammerhead Sharks off Cape Canaveral, Florida," Copeia, vol. 1985, no. 1, pp. 223$225,1985$.

[27] R. D. Kenney, R. E. Owen, and H. E. Winn, "Shark distributions off the Northeast United States from marine mammal surveys," Copeia, vol. 1985, no. 1, pp. 220-223, 1985.

[28] S. H. Gruber, D. R. Nelson, and J. F. Morrissey, "Patterns of activity and space utilization of lemon sharks, Negaprion brevirostris, in a shallow Bahamian lagoon," Bulletin of Marine Science, vol. 43, no. 1, pp. 61-76, 1988.

[29] E. A. Reyier, D. H. Adams, and R. H. Lowers, "First evidence of a high density nursery ground for the lemon shark, Negaprion brevirostris, near Cape Canaveral, Florida," Florida Scientist, vol. 71, no. 2, pp. 134-148, 2008.

[30] M. L. Dicken and A. J. Booth, "Surveys of white sharks (Carcharodon carcharias) off bathing beaches in Algoa Bay, South Africa," Marine and Freshwater Research, vol. 64, no. 6, pp. 530-539, 2013.

[31] NOAA/NMFS, Stock Assessment Report-Large Coastal Shark Complex, Blacktip and Sandbar Shark, Silver Spring, Maryland, 2006, H.M.S.M. Devision.

[32] C. A. Brown and S. H. Gruber, "Age assessment of the lemon shark, Negaprion brevirostris, using tetracycline validated vertebral centra," Copeia, no. 3, pp. 747-753, 1988.

[33] S. H. Gruber, C. A. Brown, and A. D. Henningsen, "Age and growth of the lemon shark, Negaprion brevirostris (poey), as determined by mark recapture data and the examination of tetracycline labelled vertebral centra," American Zoologist, vol. 25, no. 4, pp. A106-A106, 1985.

[34] S. H. Gruber, "Role of the lemon shark, Negaprion brevirostris (Poey) as a predator in the tropical marine environment: a multidisciplinary study," Florida Scientist, vol. 45, no. 1, pp. 4675, 1982.

[35] L. J. V. Compagno, Sharks of the Order Carcharhiniforms, Priceton University Press, Princeton, NJ, USA, 1988.

[36] B. M. Wetherbee, S. H. Gruber, and E. Cortes, "Diet, feeding habits, digestion and consumption in sharks with special reference to the lemon shark Negaprion brevirostris," NOAA Technical Report NMFS, no. 90, pp. 29-48, 1990.

[37] J. F. Morrissey and S. H. Gruber, "Habitat selection by juvenile lemon sharks, Negaprion brevirostris," Environmental Biology of Fishes, vol. 38, no. 4, pp. 311-319, 1993.
[38] J. F. Morrissey and S. H. Gruber, "Habitat selection by juvenile lemon sharks, Negaprion brevirostris," Environmental Biology of Fishes, vol. 38, no. 4, pp. 311-319, 1993.

[39] E. Cortes and S. H. Gruber, "Diet, feeding-habits and estimates of daily ration of young lemon sharks, Negaprion brevirostris (Poey)," Copeia, no. 1, pp. 204-218, 1990.

[40] P. J. Motta, T. C. Tricas, R. E. Hueter, and A. P. Summers, "Feeding mechanism and functional morphology of the jaws of the lemon shark Negaprion brevirostris (Chondrichthyes, Carcharhinidae)," Journal of Experimental Biology, vol. 200, no. 21, pp. 2765-2780, 1997.

[41] S. P. Newman, Spatial and Temporal Variation in Diet and Prey Selectivity of Nursery Bound Juvenile Lemon Sharks Around Bimini, Bahamas, in Biological Sciences, University of Plymouth, Plymouth, UK, 2003.

[42] K. A. Feldheim, S. H. Gruber, and M. V. Ashley, "The breeding biology of lemon sharks at a tropical nursery lagoon," Proceedings of the Royal Society B, vol. 269, no. 1501, pp. 1655-1661, 2002.

[43] K. A. Feldheim, S. H. Gruber, and M. V. Ashley, "Reconstruction of parental microsatellite genotypes reveals female polyandry and philopatry in the lemon shark, Negaprion brevirostris," Evolution, vol. 58, no. 10, pp. 2332-2342, 2004.

[44] A. Morgan, P. W. Cooper, T. Curtis, and G. H. Burgess, "Overview of the U.S. East coast bottom longline shark fishery, 1994-2003," Marine Fisheries Review, vol. 71, no. 1, pp. 23-38, 2009.

[45] IUCN, The IUCN Red List of Threatened Species-Negaprion Brevirostris, 2009, http://www.iucnredlist.org/details/39380/0.

[46] B. Worm, B. Davisa, L. Kettemera et al., "Global catches, exploitation rates, and rebuilding options for sharks," Marine Policy, vol. 40, pp. 194-204, 2013.

[47] M. J. Barker, S. H. Gruber, S. P. Newman, and V. Schluessel, "Spatial and ontogenetic variation in growth of nursery-bound juvenile lemon sharks, Negaprion brevirostris: a comparison of two age-assigning techniques," Environmental Biology of Fishes, vol. 72, no. 3, pp. 343-355, 2005.

[48] B. R. Franks, The Spatial Ecology and Resource Selection of Juvenile Lemon Sharks (Negaprion Brevirostris) in Their Primary Nursery Areas, Drexel University, 2007.

[49] D. D. Chapman, E. A. Babcock, S. H. Gruber et al., "Longterm natal site-fidelity by immature lemon sharks (Negaprion brevirostris) at a subtropical island," Molecular Ecology, vol. 18, no. 16, pp. 3500-3507, 2009.

[50] K. E. W. Shelden and J. L. Laake, "Comparison of the offshore distribution of southbound migrating gray whales from aerial survey data collected off Grainite Canyon, California," Journal of Cetacean Research and Management, no. 4, pp. 53-56, 2002.

[51] C. J. McDaniel, L. B. Crowder, and J. A. Priddy, "Spatial dynamics of sea turtle abundance and shrimping intensity in the U.S. Gulf of Mexico," Ecology and Society, vol. 4, no. 1, 2000.

[52] T. L. Guttridge, S. H. Gruber, B. R. Franks et al., "Deep danger: intra-specific predation risk influences habitat use and aggregation formation of juvenile lemon sharks Negaprion brevirostris," Marine Ecology Progress Series, vol. 445, pp. 279291, 2012.

[53] J. M. Fromentin et al., "Preliminary results of aerial surveys of bluefin tuna in the western Mediterranean Sea," Collective Volume of Scientific Papers ICCAT, vol. 85, no. 55, pp. 1019-1027, 2003.

[54] L. F. Sundström and S. H. Gruber, "Effects of capture and transmitter attachments on the swimming speed of large juvenile 
lemon sharks in the wild," Journal of Fish Biology, vol. 61, no. 3, pp. 834-838, 2002.

[55] S. T. Kessel, An Investigation Into the Behaviour and Population Dynamics of the Lemon Shark (Negaprion Brevirostris), in Earth and Ocean Sciences, Cardiff University, 2010.

[56] M. R. Heupel and D. M. Webber, "Trends in acoustic tracking: where are the fish going and how will we follow them," American Fisheries Society Symposium, vol. 76, pp. 219-231, 2012.

[57] A. B. Carlisle and R. M. Starr, "Habitat use, residency, and seasonal distribution of female leopard sharks Triakis semifasciata in Elkhorn Slough, California," Marine Ecology Progress Series, vol. 380, pp. 213-228, 2009.

[58] Y. P. Papastamatiou, C. G. Lowe, J. E. Caselle, and A. M. Friedlander, "Scale-dependent effects of habitat on movements and path structure of reef sharks at a predator-dominated atoll," Ecology, vol. 90, no. 4, pp. 996-1008, 2009.

[59] B. M. Wetherbee, S. H. Gruber, and R. S. Rosa, "Movement patterns of juvenile lemon sharks Negaprion brevirostris within Atol das Rocas, Brazil: a nursery characterized by tidal extremes," Marine Ecology Progress Series, vol. 343, pp. 283-293, 2007.

[60] L. A. Ortega, M. R. Heupel, P. V. Beynen, and P. J. Motta, "Movement patterns and water quality preferences of juvenile bull sharks (Carcharhinus leucas) in a Florida estuary," Environmental Biology of Fishes, vol. 84, no. 4, pp. 361-373, 2009.

[61] S. H. Gruber, D. R. Nelson, and J. F. Morrissey, "Patterns of activity and space utilization of lemon sharks, Negaprion brevirostris, in a shallow Bahamian lagoon," Bulletin of Marine Science, vol. 43, no. 1, pp. 61-76, 1988.

[62] R. D. Grubbs, Long-Term Movements, Migration, and Temporal Delineation of A Summer Nursery For Juvenile sandbar sharks in the Chesapeake Bay Region, American Fisheries Society Symposium, 2007.

[63] C. L. Conrath and J. A. Musick, "Investigations into depth and temperature habitat utilization and overwintering grounds of juvenile sandbar sharks, Carcharhinus plumbeus: the importance of near shore North Carolina waters," Environmental Biology of Fishes, vol. 82, no. 2, pp. 123-131, 2008.

[64] P. Miklos, S. M. Katzman, and J. J. Cech Jr., "Effect of temperature on oxygen consumption of the leopard shark, Triakis semifasciata," Environmental Biology of Fishes, vol. 66, no. 1, pp. 15-18, 2003.

[65] L. F. Sundström and S. H. Gruber, "Using speed-sensing transmitters to construct a bioenergetics model for subadult lemon sharks, Negaprion brevirostris (Poey), in the field," Hydrobiologia, vol. 371-372, pp. 241-247, 1998.

[66] A. W. Stoner, "Effects of environmental variables on fish feeding ecology: implications for the performance of baited fishing gear and stock assessment," Journal of Fish Biology, vol. 65, no. 6, pp. 1445-1471, 2004.

[67] K. A. Bigelow, C. H. Boggs, and X. He, "Environmental effects on swordfish and blue shark catch rates in the US North Pacific longline fishery," Fisheries Oceanography, vol. 8, no. 3, pp. 178198, 1999.

[68] W. W. Dowd, R. W. Brill, P. G. Bushnell, and J. A. Musick, "Standard and routine metabolic rates of juvenile sandbar sharks (Carcharhinus plumbeus), including the effects of body mass and acute temperature change," Fishery Bulletin, vol. 104, no. 3, pp. 323-331, 2006.

[69] M. R. Heupel and C. A. Simpfendorfer, "Movement and distribution of young bull sharks Carcharhinus leucas in a variable estuarine environment," Aquatic Biology, vol. 1, no. 3, pp. 277289, 2007.

[70] D. W. Sims, V. J. Wearmouth, E. J. Southall et al., "Hunt warm, rest cool: bioenergetic strategy underlying diel vertical migration of a benthic shark," Journal of Animal Ecology, vol. 75, no. 1, pp. 176-190, 2006.

[71] H. Marsh and D. F. Sinclair, "An experimental evaluation of dugong and sea turtle aerial survey techniques," Australian Wildlife Research, vol. 16, no. 6, pp. 639-650, 1989.

[72] J. K. Baum, R. A. Myers, D. G. Kehler, B. Worm, S. J. Harley, and P. A. Doherty, "Collapse and conservation of shark populations in the Northwest Atlantic," Science, vol. 299, no. 5605, pp. 389392, 2003.

[73] N. K. Dulvy, J. K. Baum, S. Clarke et al., "You can swim but you can't hide: the global status and conservation of oceanic pelagic sharks and rays," Aquatic Conservation, vol. 18, no. 5, pp. 459482, 2008.

[74] F. Ferretti, R. A. Myers, F. Serena, and H. K. Lotze, "Loss of large predatory sharks from the Mediterranean Sea," Conservation Biology, vol. 22, no. 4, pp. 952-964, 2008.

[75] S. T. Buckland, Introduction To Distance Sampling: Estimating Abundance of Biological Populations, University Press, Oxford, UK, 2001. 

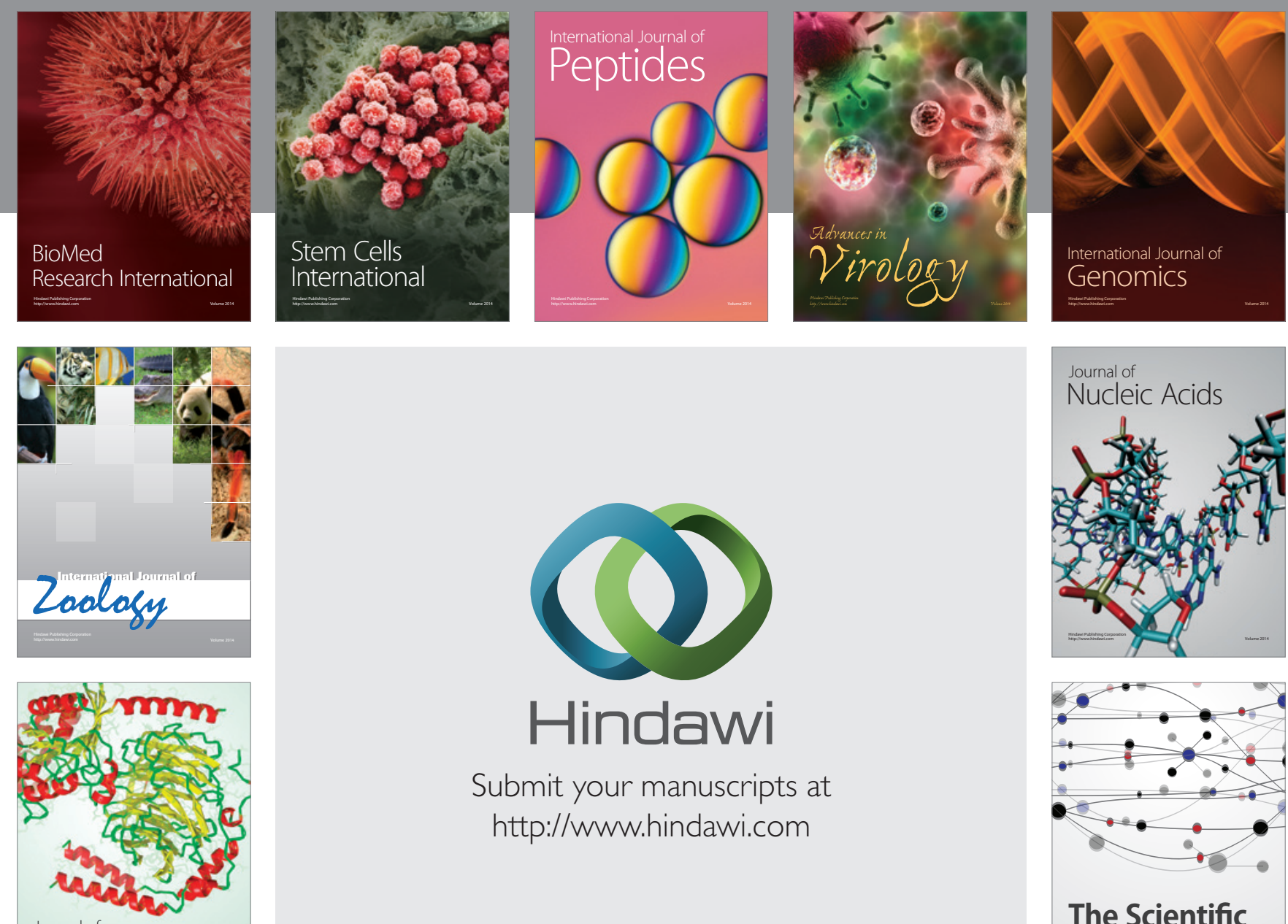

Submit your manuscripts at

http://www.hindawi.com

Journal of
Signal Transduction
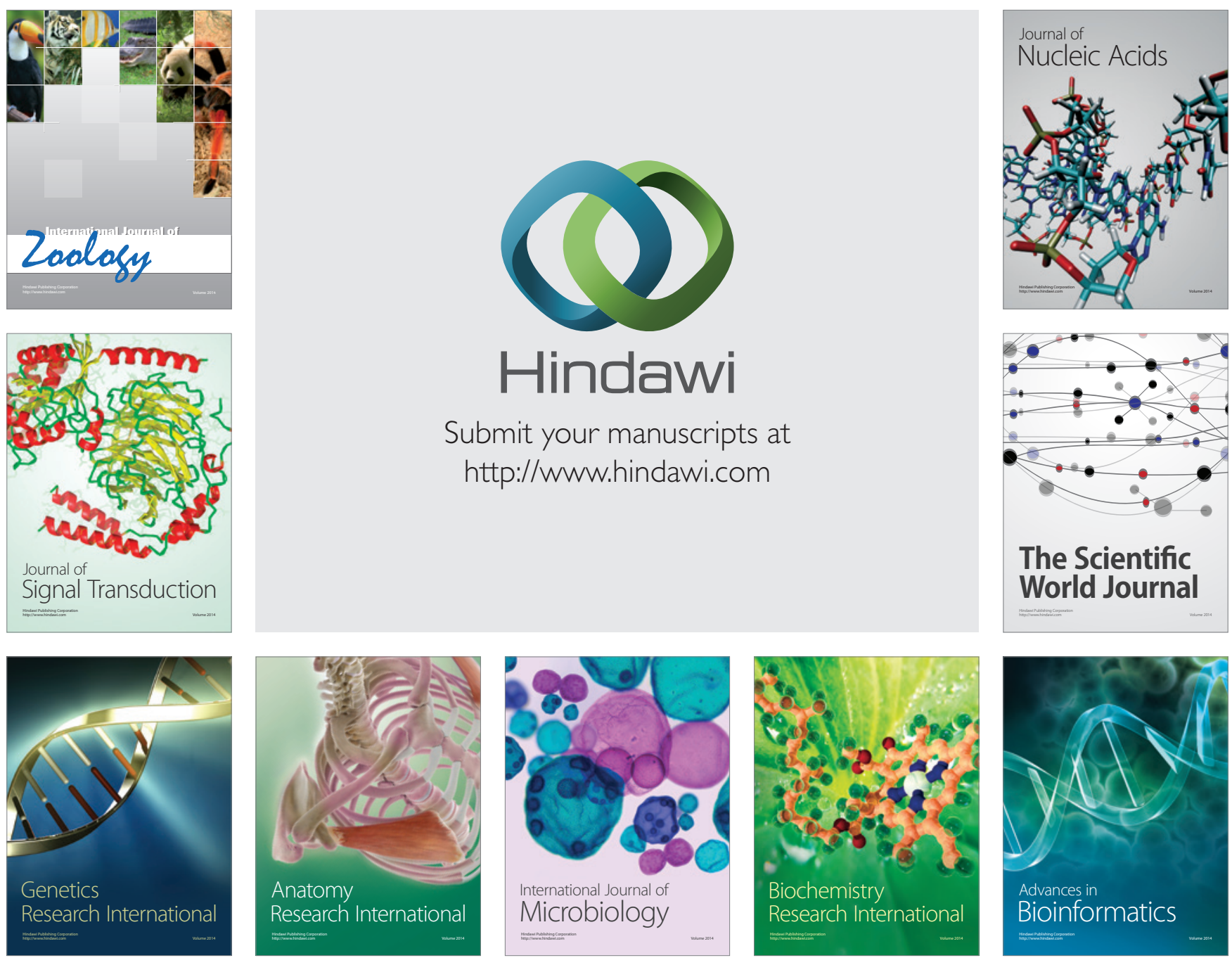

The Scientific World Journal
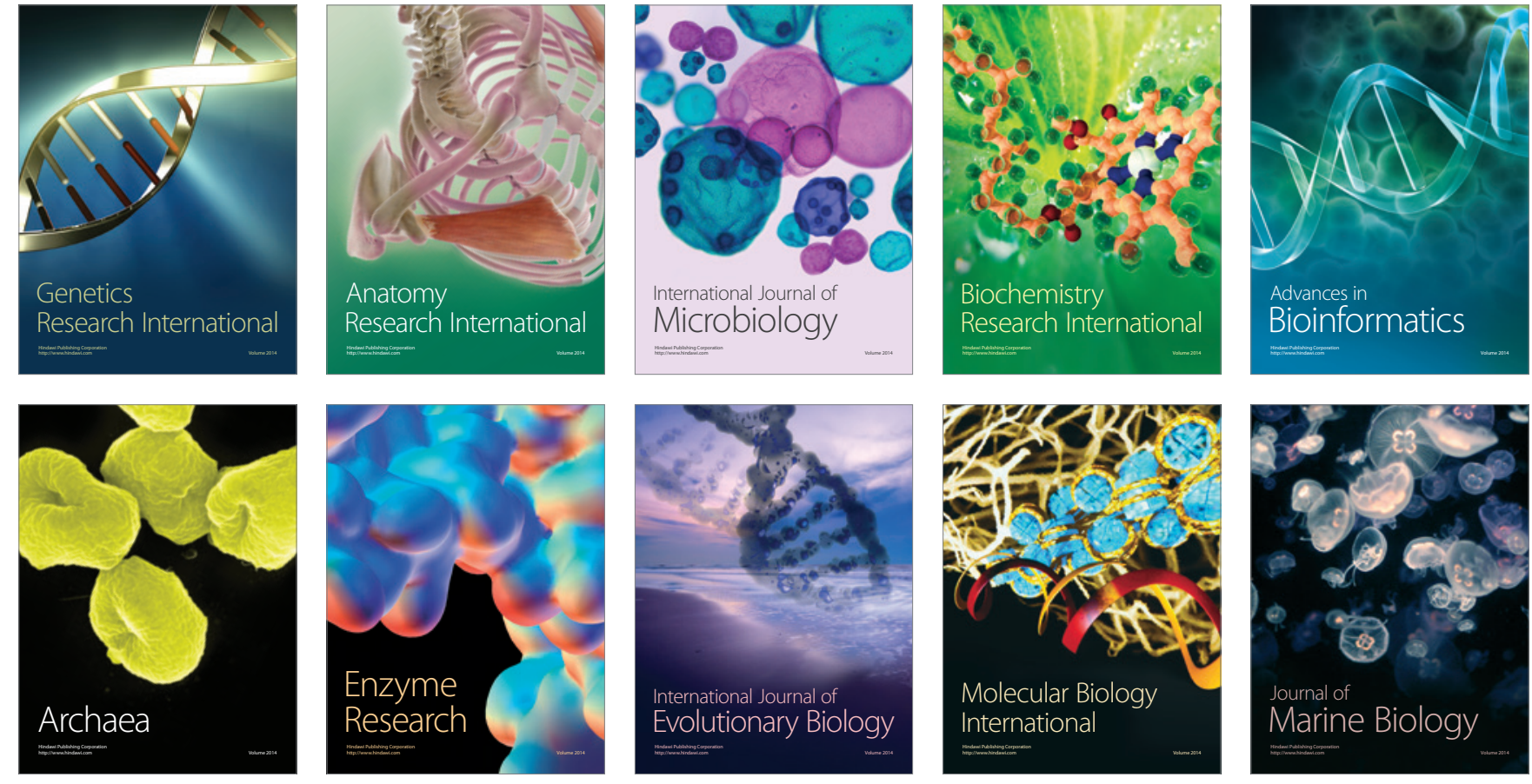